\title{
Seafood Consumption and Blood Mercury Concentrations in Jamaican Children With and Without Autism Spectrum Disorders
}

\author{
Mohammad H. Rahbar, \\ Division of Epidemiology, Human Genetics, and Environmental Sciences (EHGES), The \\ University of Texas School of Public Health at Houston, Houston, TX 77030, USA. Biostatistics/ \\ Epidemiology/Research Design (BERD) Core, Center for Clinical and Translational Sciences \\ (CCTS), The University of Texas Health Science Center at Houston (UTHealth), 6410 Fannin \\ Street, UT Professional Building Suite 1100.05, Houston, TX 77030, USA
}

\section{Maureen Samms-Vaughan,}

Department of Child Health, The University of the West Indies (UWI), Mona Campus, Kingston, Jamaica

\section{Katherine A. Loveland,}

Department of Psychiatry and Behavioral Sciences/Center of Excellence on Development and Psychopathology, and Changing Lives Through Autism Spectrum Services (C.L.A.S.S.) Clinic, UTHealth Medical School, The University of Texas Health Science Center at Houston (UTHealth), Houston, TX 77030, USA

\section{Manouchehr Ardjomand-Hessabi,}

Biostatistics/Epidemiology/Research Design (BERD) Core, Center for Clinical and Translational Sciences (CCTS), The University of Texas Health Science Center at Houston (UTHealth), 6410 Fannin Street, UT Professional Building Suite 1100.48, Houston, TX 77030, USA

\section{Zhongxue Chen,}

Biostatistics/Epidemiology/Research Design (BERD) Core, Center for Clinical and Translational Sciences (CCTS), The University of Texas Health Science Center at Houston (UTHealth), 6410 Fannin Street, UT Professional Building Suite 1100.30, Houston, TX 77030, USA

Jan Bressler, Human Genetics Center, School of Public Health, The University of Texas Health Science Center at Houston (UTHealth), Houston, TX 77030, USA

\section{Sydonnie Shakespeare-Pellington,}

Department of Child Health, The University of the West Indies (UWI), Mona Campus, Kingston, Jamaica

\section{Megan L. Grove,}

Human Genetics Center, School of Public Health, The University of Texas Health Science Center at Houston (UTHealth), Houston, TX 77030, USA

\section{Kari Bloom,}

Biostatistics/Epidemiology/Research Design (BERD) Core, Center for Clinical and Translational Sciences (CCTS), The University of Texas Health Science Center at Houston (UTHealth), 6410 Fannin Street, UT Professional Building Suite 1100.08, Houston, TX 77030, USA

\footnotetext{
(C) Springer Science+Business Media, LLC 2012

Correspondence to: Mohammad H. Rahbar, Mohammad. H. Rahbar@uth. tmc. edu.
} 
Deborah A. Pearson,

Division of Child and Adolescent Psychiatry, Department of Psychiatry and Behavioral Sciences, UTHealth Medical School, The University of Texas Health Science Center at Houston (UTHealth), Houston, TX 77030, USA

Gerald C. Lalor, and

International Centre for Environmental Nuclear Science, The University of the West Indies, Mona Campus, Kingston, Jamaica

\section{Eric Boerwinkle}

Division of Epidemiology, Human Genetics, and Environmental Sciences (EHGES), The University of Texas School of Public Health at Houston, Houston, TX 77030, USA. Human Genetics Center, School of Public Health, The University of Texas Health Science Center at Houston (UTHealth), Houston, TX 77030, USA

Mohammad H. Rahbar: Mohammad.H.Rahbar@uth.tmc.edu; Maureen Samms-Vaughan: msamms@cwjamaica.com; Katherine A. Loveland: Katherine.A.Loveland@uth.tmc.edu; Manouchehr Ardjomand-Hessabi: Manouchehr.A.Hessabi@uth.tmc.edu; Zhongxue Chen: Zhongxue.Chen@uth.tmc.edu; Jan Bressler: Jan.Bressler@uth.tmc.edu; Sydonnie Shakespeare-Pellington: sydonniesp@gmail.com; Kari Bloom: Kari.Bloom@uth.tmc.edu; Deborah A.Pearson: Deborah.A.Pearson@uth.tmc.edu; Gerald C. Lalor: gerald.lalor@uwimona.edu.jm; Eric Boerwinkle: Eric.Boerwinkle@uth.tmc.edu

\section{Abstract}

Mercury is a toxic metal shown to have harmful effects on human health. Several studies have reported high blood mercury concentrations as a risk factor for autism spectrum disorders (ASDs), while other studies have reported no such association. The goal of this study was to investigate the association between blood mercury concentrations in children and ASDs. Moreover, we investigated the role of seafood consumption in relation to blood mercury concentrations in Jamaican children. Based on data for 65 sex- and age-matched pairs (2-8 years), we used a General Linear Model to test whether there is an association between blood mercury concentrations and ASDs. After controlling for the child's frequency of seafood consumption, maternal age, and parental education, we did not find a significant difference $(P=0.61)$ between blood mercury concentrations and ASDs. However, in both cases and control groups, children who ate certain types of seafood (i.e., salt water fish, sardine, or mackerel fish) had significantly higher (all $P<0.05$ ) geometric means blood mercury concentration which were about 3.5 times that of children living in the US or Canada. Our findings also indicate that Jamaican children with parents who both had education up to high school are at a higher risk of exposure to mercury compared to children with at least one parent who had education beyond high school. Based on our findings, we recommend additional education to Jamaican parents regarding potential hazards of elevated blood mercury concentrations, and its association with seafood consumption and type of seafood.

\section{Keywords}

Autism spectrum disorders; Blood mercury concentrations; Seafood consumption; Confounding; Parental education; Jamaica

\section{Introduction}

Mercury $(\mathrm{Hg})$ is a toxic metal shown to have harmful effects on human health (Agency for Toxic Substances and Disease Registry 1999). At high exposure levels, mercury could lead to neurodevelopmental disorders including hyperactive tendon reflexes, deafness, blindness, cerebral palsy, intellectual and developmental disabilities, and general paralysis (National Research Council 2000; Counter and Buchanan 2004; Marsh et al. 1980; Harada 1995). 
Even at a lower level of exposure, mercury could affect language, learning, and attention deficits, as well as fine motor and visual-spatial organizational impairments (Counter and Buchanan 2004). However, the effects at low exposure levels (e.g., Faroe Islands, Grandjean et al. 1997; New Zealand, Counter and Buchanan 2004; Harada 1995; National Research Council 2000) are of a much more limited range and severity than those observed at high levels [Iraq (Marsh et al. 1980), Japan (Harada 1995)]; (Bose-O'Reilly et al. 2010). The Agency for Toxic Substances and Disease Registry (ATSDR 1999) recommends that a blood mercury level $>5 \mu \mathrm{g} / \mathrm{L}$ ( or $25 \mathrm{nmol} / \mathrm{L}$ ) be a reportable event (Knobeloch et al. 1995; Agency for Toxic Substances and Disease Registry 1999).

Sources of mercury in the environment include fish (Counter and Buchanan 2004), old mercury fever thermometers (though some states in the US have laws that limit the manufacturing, sale, and/or distribution of mercury fever thermometers, nEvironmental Protection Agency 2011b), previously manufactured vaccine preservatives (FDA 2010), dental amalgams (US Environmental Protection Agency 2011a), coal-fired power plants (The Texas Department of State Health Services, US Department of Health and Human Services, \& Agency for Toxic Substances and Disease Registry 2005; Northeast States for Coordinated Air Use Management 2003), and natural degassing of the earth's crust (Magos and Clarkson 2006). Human exposures to mercury can include, but are not limited to: (1) methylmercury: the most toxic form of mercury (Crespo-Lopez et al. 2007), which is acquired primarily through the consumption of contaminated foods, particularly fish, and has the greatest effect on brain development; (2) ethyl mercury: which has been the subject of recent scientific inquiry in relation to the controversial pediatric vaccine preservative thimerosal; (3) elemental mercury vapor: exposure through accidents or occupational and ritualistic practices; (4) inorganic mercury: to which humans are exposed through the use of topical mercury-based skin creams; and (5) metallic mercury in dental amalgams: which releases mercury vapors and $\mathrm{Hg}^{2+}$ in tissues (Counter and Buchanan 2004).

Consumption of seafood has been established as one of the major routes of exposure to mercury among children (Grandjean et al. 1997; Diez et al. 2009; Silbernagel et al. 2011; Myers et al. 2009) and adults (Harada 1995; Xue et al. 2007). Several studies reported significant associations between prenatal exposure to mercury from some seafood, including fish, in the maternal diet and an increased risk of adverse effects on the child's neurodevelopment (Grandjean et al. 1997; Murata et al. 1999; Steuerwald et al. 2000; Oken et al. 2005; Oken and Bellinger 2008; Jedrychowski et al. 2007; Debes et al. 2006; Julvez et al. 2010). In contrast, other studies did not find any associations between prenatal exposure to mercury from seafood consumption and the child's neurodevelopment (Axtell et al. 2000; Davidson et al. 1998, 2011; Myers et al. 2000, 2009). A study conducted in Michigan reported a significant association between fish consumption by women during pregnancy and having elevated mercury concentrations in their hair that was significantly associated with a very preterm delivery ( $₫ 35$ weeks of gestation) (Xue et al. 2007).

Autism spectrum disorders (ASDs) are characterized by having difficulties in social interaction, verbal and non-verbal communication, repetitive behavior, and sensory-motor movements (Rapin 1997; Hughes 2008). ASDs are lifelong neurodevelopmental and behavioral disorders manifesting in infancy or early childhood (Volkmar et al. 2005; Volkmar and Chawarska 2008; Genuis 2009). The prevalence of ASDs is about $1 \%$ in the US (Autism and Developmental Disabilities Monitoring Network Surveillance Year 2006 Principal Investigators and Centers for Disease Control and Prevention 2009). The number of children with a diagnosis of an ASD has been on the rise for over two decades (Blaxill et al. 2003; Autism and Developmental Disabilities Monitoring Network Surveillance Year 2006 Principal Investigators and Centers for Disease Control and Prevention 2009; King and Bearman 2009; Hertz-Picciotto and Delwiche 2009). Hertz-Picciotto and Delwiche (2009) 
evaluated the role of an expanded definition of ASDs (American Psychiatric Association 2000), diagnostic changes (Chakrabarti and Fombonne 2005; Croen et al. 2002a), and age at diagnosis in relation to the rise in incidence of ASDs. While these factors contribute to this increase (Chakrabarti and Fombonne 2005; Hertz-Picciotto and Delwiche 2009), a true rise in incidence may also be occurring (Blaxill et al. 2003; King and Bearman 2009).

The etiology of ASDs is complex and not fully understood but it is believed to be multifactorial (Gardener et al. 2011). A variety of risk factors have been associated with ASDs. These risk factors include prenatal exposures to thalidomide (Rodier and Hyman 1998), valproic acid (Christianson et al. 1994), parental age (Reichenberg et al. 2006; Hultman et al. 2002; Bilder et al. 2009; Rahbar et al. 2012), and parity (Hultman et al. 2002; Bilder et al. 2009; Larsson et al. 2005). Other risk factors are perinatal exposures that include gestational age (Bilder et al. 2009; Hultman et al. 2002; Larsson et al. 2005), rubella (Chess et al. 1978), breech presentation (Bilder et al. 2009), daily maternal smoking during early pregnancy (Hultman et al. 2002), and pesticides, including organophosphate insecticide (chlorpyrifos) (D'Amelio et al. 2005). However, due to the retrospective nature of these studies, the causality of many of these risk factors could not be definitely established. Though genetic factors play a role in ASDs (Folstein and Rosen-Sheidley 2001; Kumar and Christian 2009), most researchers believe that ASDs are caused by environmental factors, either directly (Landrigan 2010) or interactively with some genes (Hallmayer et al. 2011). Several studies have investigated the possible association between exposure to mercury and ASDs, but their findings are conflicting (DeSoto and Hitlan 2007, 2008; Fido and Al-Saad 2005; Hertz-Picciotto et al. 2010; Ip et al. 2004; Kern et al. 2007; Adams et al. 2007; Lakshmi Priya and Geetha 2010). For example, a case-control study of 40 boys (4-8 years) with autism and 40 non-affected age-matched boys from Kuwait reported a higher median mercury in the hair of children with ASD (4.50 vs. $0.30 \mu \mathrm{g} / \mathrm{g} ; P$ $<0.01$ ) (Fido and Al-Saad 2005). In contrast, the Childhood Autism Risk from Genetics and Environment (CHARGE) study, after adjusting for a variety of factors, including children's fish consumption and other mercury sources such as application of nasal spray and earwax removal products, did not find any significant difference $(P=0.75)$ between geometric mean blood mercury concentrations of 2-5-year-old children with an ASD $(0.19 \mu \mathrm{g} / \mathrm{L})$ and those of typically developing (TD) controls ( $0.28 \mu \mathrm{g} / \mathrm{L})$ (Hertz-Picciotto et al. 2010).

As an island nation, Jamaica has very specific sources of exposure to environmental contaminants, including mercury (Knight et al. 1997; Lalor 1996; Howe et al. 2005), most notably via the widespread consumption of seafood, including fish. We investigated the association between blood mercury concentrations in children with ASDs. Furthermore, as no published data are available regarding blood mercury concentrations among Jamaican children, we estimated the levels of blood mercury concentrations among children in this island.

\section{Materials and Methods}

\section{General Description}

The Jamaican Autism study is a NIH-supported age- and sex-matched case-control study that began enrollment of Jamaican children 2-8 years of age in December 2009, investigating whether environmental exposures to several heavy metals, including mercury, have a role in the onset of an ASD. Information regarding the recruitment and assessment of ASD cases and controls has been described previously (Rahbar etal. 2012). In short, we administered the Autism Diagnostic Observation Schedule (ADOS) (Lord et al. 2002) and the Autism Diagnostic Interview-Revised (ADI-R) (Rutter et al. 2003) to confirm the diagnosis of an ASD in case children. As the ADOS and ADI-R assessments take a considerable amount of time (Dixon et al. 2009), and we wished to reduce any undue burden 
on potential control children and their parents, we instead administered the Lifetime form of the Social Communication Questionnaire (SCQ) (Rutter et al. 2003) to the parents/guardians of control children to rule out symptoms of ASDs.

We also administered a pre-tested questionnaire to the parents/guardians of both cases and controls to collect demographic and socioeconomic (SES) information (e.g., ownership of a car by the family), parental levels of education, medication and immunization history of children, and potential exposure to mercury through food, with a particular focus on the types and amount of seafood consumed by children. The types of seafood considered included salt water fish, fresh water fish (pond fish, tilapia), sardine or mackerel (canned fish), tuna (canned fish), salt fish (pickled mackerel), shellfish (lobsters, crabs), and shrimp. The frequency of seafood consumption by children was measured through the number of servings (number of meals) of seafood consumed per week. At the end of each interview, the UWI project coordinator, who has received phlebotomy training, collected about $2 \mathrm{~mL}$ of venous whole blood from each child using stainless steel needles into plastic tubes containing EDTA which were prescreened for mercury, cadmium, and lead. We also collected hair samples (only from children with long hair, at least 3 in). The blood samples were frozen and stored at $-20^{\circ} \mathrm{C}$ until they were transported to the Michigan Department of Community Health (MDCH) Trace Metals Lab at ambient temperature on ice packs for trace metal analyses, including mercury.

All participating parents provided written informed consent. In addition, this study was approved by the Institutional Review Boards of the University of Texas Health Science Center at Houston (UTHealth) and the University of the West Indies in Kingston, Jamaica. The data presented herein represent an analysis of 65 matched case-control pairs. As shown below, the available data provide sufficient power to detect meaningful effect sizes for continuous variables, such as blood mercury concentrations, between any two groups compared (e.g., ASD cases and controls or those who eat or do not eat seafood).

\section{Assessment of Mercury Exposure}

The Trace Metals Lab at MDCH, certified by the Centers for Disease Control and Prevention (CDC), conducted the trace metal analyses. The whole venous blood samples were assayed for several heavy metals including mercury. MDCH followed a fully validated protocol for analyzing mercury in blood samples with detection limits of $0.3 \mu \mathrm{g} / \mathrm{L}$. Controls for mercury included bovine blood spiked with known quantities of mercury according to an established Quality Control (QC) program of the MDCH Trace Metal Lab. All samples were diluted and analyzed on a PerkinElmer Elan DRC II inductively coupled plasma mass spectrometer (PerkinElmer, Waltham, MA).

\section{Data Management}

We used double data entry to minimize data entry errors. The first entry was conducted by members of our data management team in Jamaica. Then, the completed questionnaires and forms were sent to the US and our data management team in Houston completed the second data entry. The two sets of data entry were compared and the discrepancies were resolved. After completing the data cleaning phase, the data manager selected $10 \%$ of the study forms and compared them with the corresponding entries in the database and reported that the error rate in our database was $0.05 \%$. This was done to ensure that the error rate in the data entry for all variables was below the acceptable level of $0.3 \%$ (The Centers for Disease Control and Prevention 2009b). Mercury concentration data provided by the MDCH were linked to this data set for statistical analysis. 


\section{Statistical Analysis}

Descriptive analyses were conducted to compare demographic and SES characteristics of cases and controls. As the distribution of blood mercury concentrations is skewed, we transformed data using the natural logarithm $(\ln )$ to produce a distribution that better approximated a normal distribution. The means of the $\ln$ transformed mercury concentrations were transformed to their original scale (i.e., $\mu \mathrm{g} / \mathrm{L}$ ) by applying an exponential function, herein called geometric means (i.e., Exp. [Mean $(\operatorname{lnHg})]=$ geometric mean). In addition, as this is a sex- and age-matched case-control study, we used General Linear Models (GLMs) with random effects to compare the cases and controls with respect to blood mercury concentrations. In addition, we controlled for the effect of matching by including 64 dummy variables ( $65-1=64$, one pair serving as a referent category) to represent the 65 matched pairs as described in our recent published work (Rahbar et al. 2012). Associations between the categorical exposure variables and case status were assessed using Conditional Logistic Regression (CLR). Using GLMs, we also assessed the association between mercury concentrations and various exposures of interest, including frequency of eating various kinds of seafood or fish (e.g., mackerel), maternal and paternal age at child's birth, and parental education levels. In order to minimize any potential effects of multicollinearity due to a high correlation between maternal and paternal education levels, we created a binary variable indicating whether both parents had education up to high school or at least one of the parents obtained education beyond high school. Finally, we conducted multivariable analysis using GLMs to compare the cases and controls with respect to blood mercury concentrations while controlling for potential confounding variables, including child's frequency of seafood consumption, maternal age, and parental education levels. All statistical analyses were conducted at $5 \%$ level of significance using SAS 9.2 (SAS Institute Inc. 2008).

\section{Sample Size and Power}

Based on 65 pairs of children, we have at least $80 \%$ power to detect moderate effect sizes (effect size $\searrow 0.35 *$ standard deviation (SD) of blood mercury concentrations) (Rosner 2010) between ASD cases and controls at a $5 \%$ level of significance. As such, we have at least 80 $\%$ power to detect $0.35 * \mathrm{SD}$ of blood mercury concentrations between children grouped into two categories of fish consumption (e.g., those who eat fish vs. those who do not eat fish).

\section{Results}

In our sample, $86.2 \%$ of the cases and controls were male. The mean age of cases and controls was about 65 months. The cases and controls were 96.9 and $98.5 \%$ AfroCaribbean, respectively. As expected, the case families had fewer children compared to control families ( $81.5 \%$ of the case families had $1-2$ children vs. $52.3 \%$ of the control families had $1-2$ children $)(P<0.01)$. Paternal education was significantly higher in the case group compared to controls ( $49.2 \%$ of fathers in the case group obtained education beyond high school compared to $8.2 \%$ in the control group; $P<0.01$ ). Similarly, a significantly higher level of education was obtained by mothers in the case group compared to the control group (47.7\% in the case group obtained education beyond high school vs. $19.0 \%$ in the control group; $P<0.01$ ). A comparison of the assets owned by the case families revealed that the case families' SES was significantly higher than the control group. For example, a significantly higher proportion of car ownership was reported by the ASD case families compared to controls (69.2 vs. $33.8 \% ; P<0.01)$. Demographic and socioeconomic characteristics of the cases and matched controls are reported in Table 1.

The case and control children had significant differences in their diet, including the amount of seafood consumption. The mean frequency of seafood consumption for cases was 4.12 
meals per week and the control group's was 6.06 meals per week $(P<0.01)$. The geometric mean blood mercury concentration of five cases who never ate fish was $0.15 \mu \mathrm{g} / \mathrm{L}$, which is significantly lower $(P<0.01)$ than that of the remaining cases $n=60$ who had a geometric mean blood mercury concentration of $0.75 \mu \mathrm{g} / \mathrm{L}$. Table 2 shows the frequency of seafood consumption by case status. The results show a significant upward trend for the mean blood mercury concentrations in relation to the frequency of seafood consumption for ASD cases and controls $(P<0.01$ for cases, and $P<0.01$ for controls).

In the univariable analysis, we observed a significant difference between cases and controls with respect to geometric mean blood mercury concentrations (geometric mean $\mathrm{Hg}=0.67$ $\mu \mathrm{g} / \mathrm{L}$ for cases vs. $0.99 \mu \mathrm{g} / \mathrm{L}$ for controls; $P<0.02$ ). As part of our effort to identify potential confounding variables, we found that the parental education levels were significantly higher in the case group compared to the control group [matched odds ratio $(\mathrm{MOR})=5.60,95 \% \mathrm{CI}$ $(2.16,14.50)]$. A similar comparison revealed that a significantly lower proportion of cases reported eating sardine or mackerel fish $[\mathrm{MOR}=0.22,95 \% \mathrm{CI}(0.08,0.66)]$ and salt fish (pickled mackerel) $[\mathrm{MOR}=0.22,95 \% \mathrm{CI}(0.08,0.66)]$ (Table 3$)$.

A comparison of geometric mean blood mercury concentrations between children who ate fish and those who did not eat fish revealed the following significant findings. First, geometric mean blood mercury concentrations of children who ate "sardine or mackerel fish" were $0.96 \mu \mathrm{g} / \mathrm{L}$, more than twice that of those children who did not eat these fish (geometric mean of $0.41 \mu \mathrm{g} / \mathrm{L})(P<0.01)$. Second, the geometric mean blood mercury concentrations of children who ate salt water fish $(0.95 \mu \mathrm{g} / \mathrm{L})$ were significantly higher than that of the children who did not eat these fish $(0.41 \mu \mathrm{g} / \mathrm{L})(P<0.01)$. Third, a similar comparison of the geometric mean blood mercury concentrations of the children who ate salt fish (pickled mackerel) $(0.91 \mu \mathrm{g} / \mathrm{L})$ was $45 \%$ more than that of children who did not eat salt fish (pickled mackerel) $(P<0.04)$. Comparisons of geometric mean blood mercury concentrations for other exposure variables are displayed in Table 4.

In our final multivariable model, we compared the geometric mean blood mercury concentrations between cases and controls, while controlling for parental education levels, maternal age, and frequency of seafood consumption. The adjusted geometric mean blood mercury concentration for cases and controls were $0.75 \mu \mathrm{g} / \mathrm{L}$ and $0.82 \mu \mathrm{g} / \mathrm{L}$, respectively. However, the adjusted $P$ value of 0.61 indicated no significant association between blood mercury concentrations and ASD status. Univariable and multivariable results are shown in Table 5.

\section{Discussion}

\section{Blood Mercury Concentrations and ASD}

Our findings do not support an association between blood mercury concentrations measured in Jamaican children 2-8 years of age and ASD case status. Even though in the univariable analysis we observed a significant difference between ASD cases and controls with respect to their geometric mean blood mercury concentrations (as shown in Table 5), when adjusted for major confounding variables including frequency of seafood consumption, parental education, and maternal age, there is no evidence to indicate an association between ASD status in children and elevated blood mercury concentrations. It is important to note that the blood mercury concentrations in this study represent mercury exposure during the postnatal period. As we do not have information regarding the mercury exposure during the perinatal and prenatal periods, reflective of mother's fish consumption during these periods, we do not know how much of our mercury exposure is attributed to exposures in other periods. Therefore, we could not evaluate the role of mercury exposures in other periods in relation to ASDs. 
These findings are consistent with the results published by the CHARGE study (HertzPicciotto et al. 2010), which reported similar findings from California. However, the CHARGE study reported lower blood mercury concentrations than our study (HertzPicciotto et al. 2010). On the other hand, our results are in contrast with findings from several other studies that reported an association between mercury and a diagnosis of an ASD in children (Fido and Al-Saad 2005; Adams et al. 2007; Lakshmi Priya and Geetha 2010; DeSoto and Hitlan 2007). For example, Fido and Al-Saad (2005) studied 40 ASD cases and 40 controls and reported a higher level of median mercury in the hair of children with an ASD $(4.50 \mu \mathrm{g} / \mathrm{g}$ in cases vs. $0.30 \mu \mathrm{g} / \mathrm{g}$ in controls; $P<0.01)$ (Fido and Al-Saad 2005). Another study from Arizona that involved 15 children with an ASD and 11 TD children assessed mercury in teeth and reported a higher mean level of mercury in teeth for the ASD group $(0.15 \mu \mathrm{g} / \mathrm{g}$ in cases vs. $0.07 \mu \mathrm{g} / \mathrm{g}$ in controls; $P<0.05)$ (Adams et al. 2007). Moreover, Lakshmi Priya and Geetha (2010) reported significantly higher $(P<0.01)$ levels of mercury in both hair and nail samples of 45 ASD cases with different grades of severity of autism $\left[n_{1}=15\right.$ with Low Functioning Autism (LFA), $n_{2}=15$ with Medium Functioning Autism (MFA), and $n_{3}=15$ with High Functioning Autism (HFA)]) compared to a TD control group $(n=50)$. Mercury levels in the hair were higher in children with LFA compared to children with MFA or HFA (Lakshmi Priya and Geetha 2010).

However, it is important to note that these three studies (Fido and Al-Saad 2005; Adams et al. 2007; Lakshmi Priya and Geetha 2010) did not control for any potential confounding effects, which may have adversely affected their findings. In our study, we found significant differences between our case and control groups with respect to the frequency of seafood consumption $(P<0.01)$, parental education $(P<0.01)$, and maternal age $(P=0.03)$. In addition, we found significant or marginally significant associations between blood mercury concentrations in children and frequency of seafood consumption $(P<0.01)$; parental education $(P=0.04)$; and maternal age $(P=0.07)$. In the following, we discuss the role of confounding and other methodological differences in the aforementioned studies with a particular focus on methods of assessment of mercury exposure, study design, and statistical analysis methods that may have contributed to the conflicting results between our study and some other studies (Fido and Al-Saad 2005; Adams et al. 2007; Lakshmi Priya and Geetha 2010; Ip et al. 2004; Kern et al. 2007; DeSoto and Hitlan 2007, 2008).

\section{Role of Seafood Consumption}

In this study, we observed a significant difference between the ASD case and control groups with respect to the types of fish consumed. For example, children with ASD consumed significantly lower amounts of sardine and mackerel compared to children without ASD $(P$ $<0.01)$. A similar trend was observed for salt water fish consumption, but the difference was marginally significant $(P=0.07)$. There could be several reasons for the relationship between ASD and seafood consumption but an important factor based on the available literature is that, compared with TD children, ASD cases experience higher levels of gastrointestinal (GI) problems (70 vs. $28 \%$ ) (Valicenti-McDermott et al. 2006), a higher incidence of constipation (33.9 vs. $17.6 \%$ ) (Horvath and Perman 2002), and feeding issues which may result in food selectivity for children with ASD (24.5 vs. $16.1 \%$ ) (Ibrahim et al. 2009). Moreover, ASD cases who lived in families that did not own a car (a surrogate measure for SES) reported a significantly $(P=0.02)$ higher frequency of seafood consumption. As in our study, the ASD case families had a significantly $(P<0.01)$ higher SES than that of the control group, this could be another reason for observing a lower level of seafood consumption by the ASD cases. The CHARGE study also reported a lower level of fish consumption among the children with an ASD (Hertz-Picciotto et al. 2010). On the other hand, our findings indicate an upward trend for the geometric mean blood mercury concentrations in relation to the frequency of seafood consumption. For example, in 
comparison with children with ASD who ate up to three seafood meals per week, ASD cases who consumed more than three seafood meals per week had a significantly higher geometric mean blood mercury concentration $(P<0.01)$. These findings suggest that seafood consumption could be a major confounding variable when assessing the association between blood mercury concentrations and an ASD in children. Consistent with our findings, the CHARGE study, also identified fish consumption as a major confounding variable in their investigation of the association between blood mercury concentrations and ASDs and have controlled for its effect in their final multivariable models (Hertz-Picciotto et al. 2010).

\section{Role of Parental Education}

In this study, we observed a significant difference in the levels of parental education between the ASD case and control groups. Specifically, $66.7 \%$ of parents of children with an ASD had education beyond high school compared to $23.7 \%$ for children in the control group $(P<0.01)$. Several other studies also reported an association between parental education and ASD status (King and Bearman 2011; Sasanfar et al. 2010; Croen et al. 2002b). For example, Croen et al. (2002b) reported that, compared to mothers without any postgraduate education, mothers who had a postgraduate degree had an increased risk of having a child with an ASD [adjusted relative risk $\left(\mathrm{RR}_{\mathrm{a}}\right)=2.0,95 \% \mathrm{CI}(1.7-2.3)$ ] (Croen et al. 2002b). On the other hand, in our study, parental education levels were associated with blood mercury concentrations in Jamaican children. If at least one of the parents had education beyond high school, then the geometric mean blood concentration in their children was significantly lower than children whose parents both had education up to high school $(0.61 \mathrm{vs.} 1.01 \mu \mathrm{g} / \mathrm{L} ; P<0.04)$. In addition, we found that children whose parents both had education up to high school reported a higher frequency of seafood consumption compared to children with at least one parent who had education beyond high school [mean weekly number of seafood meals consumed $(6.14$ vs. $4.02 ; P<0.01)$ ]. These findings suggest that parental education levels could be another potential source of confounding when assessing the association between blood mercury concentrations and ASDs, and the inconsistent findings reported by some of these studies could be due to the fact that they have not controlled for any potential confounders, including parental education. In the CHARGE study, while the association between maternal education and blood mercury concentration in children was not statistically significant, they did control for maternal education in their final multivariable models (Hertz-Picciotto et al. 2010).

\section{Role of Maternal Age}

In our study, maternal age of ASD cases was significantly $(P=0.03)$ higher than that of the control group. Specifically, $26.2 \%$ of mothers of ASD cases were older than 35 years compared to $11.3 \%$ in the control group. Others and we have reported that a higher maternal age at the time of the child's birth is associated with an increased risk for an ASD in the offspring. (Croen et al. 2002b; Durkin et al., 2008; Bilder et al. 2009; Shelton et al. 2010; Rahbar et al. 2012). On the other hand, though marginally significant, we found that children with younger mothers had a slightly higher geometric mean blood mercury concentration than children with older mothers $(0.88 \mathrm{vs} .0 .52 \mu \mathrm{g} / \mathrm{L} ; P=0.07)$. Although Grandjean et al. (1997) reported a non-significant correlation between maternal age at childbirth and cord blood mercury concentrations $(r=0.05, P=0.12)$ (Grandjean et al. 1997) in the Faroe Islands study, a study from Spain reported (Freire et al. 2010) significantly higher total hair mercury levels $(P<0.05)$ in children with mothers younger than 32 years of age as compared to children born to mothers aged 32 years or older at childbirth. In addition, Lando et al. (2011) reported that women aged 18-45 years had a lower level of knowledge than women older than 45 years regarding the association between fish consumption and elevated mercury levels as well as its associated risks (Lando and Zhang 2011). These findings suggest not only that the effect of maternal age on blood 
mercury concentrations among children could be due to awareness and knowledge of the mother regarding mercury in fish, but also that maternal age could be an important source of confounding when assessing the association between blood mercury concentrations and ASD case status. In this study, we have controlled for potential confounding by maternal age, but the findings reported in other studies that have relied only on univariable analysis (Fido and Al-Saad 2005; Adams et al. 2007; Lakshmi Priya and Geetha 2010; Ip et al. 2004; Kern et al. 2007; DeSoto and Hitlan 2007, 2008) could be subjected to confounding by maternal age.

\section{Role of SES Status}

Depending on the geographic region, SES of parents could play a role in seafood consumption among children. A study from Toronto, Canada, reported that lower SES was associated with lower levels of fish consumption (Sontrop et al. 2007). In contrast, Trondsen et al. (2003) conducted a study in Norway and reported that infrequent fish consumption is significantly associated with high income (Trondsen et al. 2003). In our study, we found that children who lived in families that did not own a car (a surrogate for lower SES) reported a significantly $(P=0.02)$ higher frequency of seafood consumption. Moreover, children with a higher consumption of seafood had a higher geometric mean blood mercury concentration compared to children with lower levels of seafood consumption (1.60 vs. $0.61 \mu \mathrm{g} / \mathrm{L} ; P$ $<0.01)$. As we have already reported that there was a significant association between SES status (car ownership) of the parents and ASD status of the children $(P<0.01)$, we explored the role of SES as a potential confounder when assessing the association between blood mercury concentrations and ASD status. However, in order to avoid multicollinearity (Rahbar et al. 2012) due to a high correlation between SES and parental education levels, we did not keep SES in our final GLM. Considering a strong association between SES and parental education levels, we believe that parental education serves as a reliable surrogate for SES. Therefore, we are confident that controlling for paternal education levels, frequency of fish consumption, and maternal age in the final model have resulted in appropriate adjusted geometric mean blood mercury concentrations for ASD case and control groups.

\section{Assessment of Mercury Exposure}

It should be noted that care must be taken when identifying the form of mercury being assessed. Hair contains total mercury (inorganic and methyl), with methylmercury comprising 70-90\%. Due to this and other factors, researchers consider total mercury levels in hair to be a better biomarker of exposure to methylmercury (Chen et al. 2002; Berglund et al. 2005). However, it has been shown that in island communities and populations in which seafood is consumed, there is a bioaccumulation of mercury exposure through diet (Dorea 2006, 2008, 2009). Based on a meta-analysis, Ng et al. (2007) reported a weighted correlation coefficient of 0.61 between hair mercury levels and blood mercury concentrations ( $\mathrm{Ng}$ et al. 2007). It has also been documented that blood mercury concentrations are affected by chelation therapy and diet (e.g., fish consumption) 2 months prior to assessment, but hair mercury levels are not similarly affected (Aschner 2008). In our study, we planned to collect both blood and hair for assessment of mercury, but as the majority of Jamaican boys keep short hair, in accordance with their cultural values, and the ratio of boys to girls with ASD is about 4:1, we only have hair samples from about $20 \%$ of the ASD cases and their age- and sex-matched controls. Therefore, we could only assay and report blood mercury concentrations here. As the half-life of mercury in blood is 60-90 days (Clarkson et al. 2003), we considered blood mercury concentrations in our study mainly to represent mercury exposure during the postnatal period. The MDCH Trace Metal Lab used bovine blood spiked with known quantities of mercury as controls to ensure the reliability of assessment of mercury in blood samples. While we have taken the necessary steps to obtain 
reliable mercury exposures in blood, we acknowledge the possibility that the mercury in hair that is used by other studies may represent a different period of exposure, which could result in different findings.

\section{Design and Analysis Methods}

A case-control study design is appropriate for identifying environmental risk factors for ASDs (Song and Chung 2010). However, as Palmer (2010) highlighted, a lack of association between mercury and ASDs based on a case-control study, without testing for potential gene-environment interactions, should not be interpreted as an indication of the safety of exposure to mercury for all (Palmer 2010). In other words, while we did not find differences between ASD case and control groups with respect to levels of mercury exposure, it is possible that there will be differences in individual susceptibility to mercury. We recognize this issue and acknowledge that a formal test for gene-environment interactions will require a much larger sample size of ASD cases and controls than the 65 matched pairs that we analyzed in this study. On the other hand, even though, in our study with 65 matched pairs, we have shown that we have at least $80 \%$ power to detect an effect size of 0.35 SDs between ASD case and control groups, some other studies still suffered from inadequate sample size and power. For example, Fido and Al-Saad (2005) reported significantly higher levels of mercury in hair among 40 ASD cases compared with 40 controls $(P<0.01)$, but they have not provide any justification for the sample size chosen and did not provide any estimates for statistical power (Fido and Al-Saad 2005). Some other studies suffered from applying inappropriate statistical analysis. For example, a cross-sectional study conducted in Taiwan (82 ASD cases vs. 55 controls), Ip et al. (2004), reported no significant difference between the ASD and control groups with respect to arithmetic mean blood mercury concentrations even though the means were $19.53 \mathrm{nmol} / \mathrm{L}$ for ASD cases and $17.68 \mathrm{nmol} / \mathrm{L}$ for controls (or equivalently $3.91 \mu \mathrm{g} / \mathrm{L}$ for the cases vs. $3.54 \mu \mathrm{g} / \mathrm{L}$ for the controls), respectively (Ip et al. 2004). However, DeSoto and Hitlan (2007) questioned their findings and after reanalyzing the data set used by Ip et al. (2004) reported a statistically significant relationship between blood mercury concentration and ASDs $(P<0.02)$ (DeSoto and Hitlan 2007). Although DeSoto and Hitlan (2008) corrected the $P$ value reported by Ip et al. (2004), they did not control for potential confounding variables that may have affected this association. Given that children living in Taiwan consume seafood, it is not clear whether adjustment for the food consumed and other potential confounders, such as age of parents and their education, may have changed the findings of their study. Moreover, Kern et al. (2007) conducted an age-, sex-, and ethnicity-matched case-control study (45 matched pairs) in Dallas, Texas and reported no significant association between ASD status and level of mercury in the hair. However, for analysis, they used a nonparametric test (KruskalWallis test) which assumes independence between the measurements in the two samples (Kern et al. 2007). As their study design was a matched case-control design, the measurements may be dependent. Therefore, they should have used a procedure that did not assume independence among the measurements (e.g., Friedman's nonparametric test). In addition, Kern et al. (2007) did not control for any potential confounders. In summary, when planning case-control studies to investigate environmental risk factors for ASD, the evidence presented here suggests not only the need for a carefully designed study with adequate power but also the application of appropriate statistical analysis that controls for potential confounders. In addition, special effort should be made to assess geneenvironment interaction particularly for ubiquitous environmental exposures (e.g., exposure to mercury in a population with high fish consumption).

\section{Blood Mercury Concentrations in Jamaican Children}

To our knowledge, we are the first to report on blood mercury concentrations in Jamaican children. We observed that children living in Jamaica have higher blood mercury 
concentrations than children in developed countries. For example, the geometric mean blood mercury concentration of the control group in our Jamaican study was $0.99 \mu \mathrm{g} / \mathrm{L}$, nearly 3.5 times that of a sample of 2-5-year-old TD children in California (0.99 vs. $0.28 \mu \mathrm{g} / \mathrm{L})$ (HertzPicciotto et al. 2010). Similarly, the National Health and Nutrition Examination Survey (NHANES) (2003-2004) reported a geometric mean blood mercury concentration of 0.33 with a $95 \%$ CI (0.285-0.372) for young children (1-5 years) in the US (The Centers for Disease Control and Prevention 2009a). Even though our sample included children 2-8 years of age, the geometric mean blood concentration in our control group is almost three times that of the NHANES survey. In addition, the geometric mean blood mercury concentration of the control group in our Jamaican study was about three times that of a sample of children 6-19 years of age from the Canadian Health Measures Survey (CHMS), who had a geometric mean blood mercury concentration of $0.31 \mu \mathrm{g} / \mathrm{L}$ (Wong and Lye 2008). However, when compared to the mean blood mercury concentration of a sample of 4-11-year-old TD children in Hong Kong, the arithmetic mean blood mercury concentration from our Jamaican control group was much lower (1.27 vs. $3.54 \mu \mathrm{g} / \mathrm{L}$ ) (Ip et al. 2004). Furthermore, the arithmetic mean blood mercury concentration of children in the control group of our Jamaican study was much lower than that of children who live near gold mines in the eastern part of Ecuador (1.27 vs. $18.2 \mu \mathrm{g} / \mathrm{L}$ ) and another community in the central part of Ecuador that does not have gold mines (1.27 vs. $2.4 \mu \mathrm{g} / \mathrm{L}$ ) (Counter et al. 2002). On the other hand, considering a correlation of 0.33 between mercury concentrations in cord-blood and mercury levels in hair of children at age 7 (Grandjean et al. 1997) and the geometric mean of $22.9 \mu \mathrm{g} / \mathrm{L}$ in cord-blood from the Faroe Islands cohort (Grandjean et al. 1997), we speculate that Jamaican children have lower levels of blood mercury concentrations than children in the Faroe Islands.

Although blood mercury concentrations in Jamaican children are higher than those reported for children in the US or Canada (Hertz-Picciotto et al. 2010; The Centers for Disease Control and Prevention 2009a; Wong and Lye 2008), when compared to other developing countries in a similar setting (island communities), Jamaican children have a lower level of blood mercury concentration (Ip et al. 2004; Counter et al. 2002; Grandjean et al. 1997). However, evaluation of the public health significance of mercury blood concentration among children require establishment of a baseline level in the general population (Schober et al. 2003). Several countries in different geographic regions have established baseline blood mercury concentrations among children and adults. In addition, to the NHANES survey in the US (The Centers for Disease Control and Prevention 2009a), the CHMS in Canada (Wong and Lye 2008), and the German Environmental Survey on Children (GerES IV) (2001-2002), has established a baseline blood mercury concentration of $1.0 \mu \mathrm{g} / \mathrm{L}$ for children (age 6-12 years) with fish consumption (Wilhelm et al. 2006). Furthermore, the International Commission on Occupational Health (ICOH) and the International Union of Pure and Applied Chemistry (IUPAC) Commission on Toxicology recommends that the blood concentration of mercury in people who do not eat fish should be $2 \mu \mathrm{g} / \mathrm{L}$ (Agency for Toxic Substances and Disease Registry 1999). In our study, we found that only five children (all five belong to ASD case group) did not consume fish and all five had blood mercury concentrations below the limits of detection of the assay $(0.30 \mu \mathrm{g} / \mathrm{L})$. However, among the other 125 children who reported consuming seafood, only two (1.6\%) children had blood mercury concentrations exceeding the reportable threshold level of $5 \mu \mathrm{g} / \mathrm{L}$ set by ATSDR (Knobeloch et al. 1995; Agency for Toxic Substances and Disease Registry 1999). A few studies reported baseline blood mercury concentrations for ASD cases in different populations. For example, Ip et al. (2004) reported a mean blood mercury concentration of $19.53 \mathrm{nmol} / \mathrm{L}(3.91 \mu \mathrm{g} / \mathrm{L}$ ) for children with ASD (age 4-11 years) in Hong Kong (Ip et al. 2004). However, the CHARGE study reported a geometric mean blood mercury concentration of $0.19 \mu \mathrm{g} / \mathrm{L}$ for children with ASD (2-5 years) who live in California (Hertz- 
Picciotto et al. 2010). Our study shows that the baseline geometric mean blood mercury concentration for Jamaican children ( $2-8$ years) with ASD is $0.67 \mu \mathrm{g} / \mathrm{L}$.

\section{Seafood Consumption and Blood Mercury Concentrations}

Residents of island communities usually consume a higher amount of seafood, including fish. Seafood consumption is a major source of exposure to mercury for young children (Oken and Bellinger 2008; Silbernagel et al. 2011) and pregnant women (Xue et al. 2007). Types of seafood or fish consumed may have different effects on mean blood mercury concentrations. Silbernagel et al. (2011) classified fish in terms of contaminant levels of mercury (lowest, medium to high, and highest). According to their classification, mackerel is classified in the highest contaminant mercury category and sardine and shellfish are classified in the lowest contaminant mercury category (Silbernagel et al. 2011). However, depending on the type of tuna, tuna could be included in any of the three categories of contaminant levels of mercury (Silbernagel et al. 2011; FDA 2011). Our result showed that children who consumed salt fish (pickled mackerel) had a significantly higher geometric mean blood mercury concentration than the children who did not eat salt fish (pickled mackerel) $(0.91$ vs. $0.50 \mu \mathrm{g} / \mathrm{L} ; P=0.04)$. Moreover, in this study, children who ate shellfish (lobster and/or crab) had a geometric mean blood mercury concentration of $3.21 \mu \mathrm{g} / \mathrm{L}$, more than three times that of children who ate fresh water fish (pond fish and/or tilapia) who had a geometric mean blood mercury concentration of $1.01 \mu \mathrm{g} / \mathrm{L}$. Diez et al. (2009) reported that children ( $0-4$ years) who ate fish frequently (more than four times per week) had a threefold mean total mercury level in hair compared with those who did not consume fish (1.40 vs. $0.49 \mu \mathrm{g} / \mathrm{g}$ ) (Diez et al. 2009). In addition, a study from Bolivia reported significantly higher $(P<0.01)$ mercury levels in the hair of mothers and children who ate at least one daily serving of fish compared to those who consumed at most one serving of fish per week (Monrroy et al. 2008). Xue et al. (2007) reported the effects of the type of fish consumed and the frequency of consumption on the levels of mercury in hair. For example, when adjusted for maternal characteristics, consuming canned fish in more than 24 meals per 6 months resulted in a higher adjusted geometric mean mercury level in the hair of pregnant women $[0.38 \mu \mathrm{g} / \mathrm{g}, 95 \% \mathrm{CI}(0.29-0.49)]$, compared to pregnant women who did not consume any fish [0.24 $\mu \mathrm{g} / \mathrm{g}, 95 \% \mathrm{CI}(0.19-0.32)]$ (Xue et al. 2007).

\section{Role of Mercury in Neurodevelopmental Disorders}

Several studies investigated the role of exposure to mercury in neurodevelopmental disorders, especially in populations that consume fish. Some of these studies have focused on investigating the effect of exposure to mercury during the prenatal and postnatal periods and have reported conflicting findings (Llop et al. 2012). For example, some of these studies demonstrated an association between mercury in maternal diets (prenatal exposure to mercury) and neurodevelopment, with a specific focus on language development and attention (Grandjean et al. 1997; Debes et al. 2006), latencies in auditory brainstem (Murata et al. 1999), functional abilities and behavioral status (Steuerwald et al. 2000), visual recognition memory (Oken et al. 2005), visual motor functions (Oken and Bellinger 2008), mental and psychomotor development (Jedrychowski et al. 2007), latency on visual information processing and attention function (Julvez et al. 2010), and cognition (Freire et al. 2010). On the other hand, reports from the Seychelles Child Development Study (SCDS) did not indicate any associations between prenatal and postnatal exposure to mercury from seafood consumption and neurodevelopmental test scores in children at different ages who were followed until age 17 years (Axtell et al. 2000; Davidson et al. 1998, 2011; Myers et al. $2000,2009)$. Some of these studies reported effect modifications by sex. For example, Llop et al. (2012) reported an association between prenatal exposure to mercury with mental or psychomotor developmental delays in female infants, but they did not find an overall association (Llop et al. 2012). On the other hand, the age at which children are assessed for 
mercury exposure and their neurodevelopment appears to have a role in this association. For example Jedrychowski et al. (2007) demonstrated that in children at 12 months of age, there is a significant $(P<0.01)$ association between mercury exposure and poor cognitive or psychomotor function, but the association could not be confirmed in children at 24 and 36 months of age (Jedrychowski et al. 2007). In this study, we have not assessed any specific neurodevelopmental disorders other than ASDs. Therefore, it would be difficult to draw any conclusions regarding the effects of mercury on neurodevelopment other than the diagnosis of an ASD in Jamaican children.

\section{Risk-Benefit of Seafood Consumption}

Seafood, particularly due to the omega-3 polyunsaturated fatty acids (PUFA) in fish, is considered beneficial for human health (Kris-Etherton et al. 2002). Some studies have reported that dietary intake of omega-3 PUFA and fish are associated with better cognitive performance (Vinot et al. 2011; Fedorova and Salem Jr. 2006; Kalmijn et al. 2004; Ginsberg and Toal 2009; MacLean et al. 2005; Oken et al. 2005). Considering that fish consumption could have both beneficial and potentially harmful effects, it would be difficult to provide evidence-based guidelines for seafood consumption for use by the public without conducting a risk-benefit analysis (Mozaffarian 2009; Turyk et al. 2012). However, the State of Pennsylvania in the US provided an advisory for fish consumption in 2012 that guides the public regarding frequency of fish consumption (Pennsylvania Fish and Boat Commission 2012). Australia and New Zealand have jointly published guidelines for seafood consumption (Food Standards Australia New Zealand 2011).

Each population has a different level of fish consumption that could have an effect on combinations of mercury and PUFA intake. In addition, due to complex assumptions for deriving risk-benefit balance, the applicability of an optimal strategy from one population to another can only be done only if it is ascertained that the other population eats the same fish diet with the same mercury-PUFA balance (Stern and Korn 2011). Therefore, by conducting a risk-benefit analysis for the Jamaican population, one could develop an optimal strategy for seafood consumption that maximizes the benefits while minimizing the potential risk to their population.

In summary, although Jamaican children consume large amounts of seafood and their blood mercury concentrations appear to be much higher than those of children in the US and Canada, we have not found any associations between blood mercury concentrations and ASD case status. As we have not assessed neurodevelopmental disorders other than ASDs, it would be difficult to draw any evidence-based conclusions regarding the effects of mercury on other neurodevelopment disorders in Jamaican children. However, others have reported associations between blood mercury and other neurodevelopmental disorders including adverse effects on verbal learning and memory (Grandjean et al. 1997). Although, we cannot make any specific recommendations regarding safe levels of seafood consumption for Jamaican children, we do believe, however, that vulnerable groups (pregnant women and children) should continue to eat seafood, but they should only consume seafood with lower risk of mercury contamination. Hence, the Jamaican Government may benefit from educating the public, with an emphasis on parents, by publishing an advisory for mercury in seafood, particularly fish (Jakus et al. 2002; Shimshack et al. 2007; Pennsylvania Fish and Boat Commission 2012). Furthermore, we believe that Jamaicans will benefit from conducting a risk-benefit analysis (Turyk et al. 2012) that balances the risks and benefits of seafood consumption by the public. 


\section{Limitations}

We acknowledge several limitations in this study. First, as the control children for this study are selected to match the ASD cases by sex and age from the Kingston area, they may not represent a random sample from the population of all children in Jamaica. Therefore, the findings reported regarding the blood mercury concentrations may not be generalizable to children all over Jamaica. Second, the data presented here suggest that our control children were more likely to come from a lower SES group than our ASD cases. In addition, as we have shown, SES was associated with blood mercury concentrations. As SES was significantly associated with parental education, in order to avoid multicollinearity, we did not control for SES in our final model. However, we believe that controlling for parental education has indirectly controlled for potential confounding effects of SES when assessing the association between exposure to mercury and ASDs. Moreover, in this study we only assessed seafood consumption in children but not in their parents. However, we do acknowledge that maternal seafood consumption is important for the child's prenatal and neonatal mercury exposure. Furthermore, even though the frequency of seafood consumption is measured through a previously utilized and culturally appropriate food questionnaire in Jamaica, the question regarding assessment of frequency of eating sardine and mackerel were not separate. In other words, we asked how many servings of sardine or mackerel the children ate per week. This limited our ability to assess the individual effect of sardine and mackerel on the blood mercury concentrations in children. In addition, as we have used this survey to assess seafood consumption by children $2-8$ years of age, we would like to emphasize that $98.5 \%$ of the children were at least 3 years or older. Though we have shown that seafood consumption is common in Jamaican children, particularly among children 3 years or older, this does not rule out the possibility of recall bias.

\section{Conclusion}

In this study, we have shown that, prior to adjusting for potential confounding variables, there was a significant association between ASD status and having elevated blood mercury concentrations in Jamaican children 2-8 years of age. However, after adjusting for frequency of seafood consumption, parental education levels, and maternal age in a multivariable general linear regression model, we did not find a significant association between ASDs and blood mercury concentrations. In addition, we have demonstrated that children living in Jamaica have higher blood mercury concentrations than children in developed countries, including the US and Canada. As higher levels of parental education was associated with lower mean blood mercury concentrations in children, we recommend development of appropriate interventions for increasing parents' education and knowledge regarding the effects of excessive consumption of seafood on blood mercury concentration in children.

\section{Acknowledgments}

This research is co-funded by the Eunice Kennedy Shriver National Institute of Child Health and Human Development (NICHD) and the National Institutes of Health Fogarty International Center (NIH-FIC) by a grant [R21HD057808] awarded to the University of Texas Health Science Center at Houston (UTHealth). We also acknowledge the support provided by the Biostatistics/Epidemiology/Research Design (BERD) component of the Center for Clinical and Translational Sciences (CCTS) for this project. CCTS is mainly funded by the NIH Centers for Translational Science Award (NIH CTSA) Grant (UL1 RR024148), awarded to the University of Texas Health Science Center at Houston in 2006 by the National Center for Research Resources (NCRR). The content is solely the responsibility of the authors and does not necessarily represent the official views of the NICHD or the NIH-FIC or the NCRR. Finally, we acknowledge contributions by colleagues in the Trace Metals Lab at the department of Michigan Department of Community Health $(\mathrm{MDCH})$ for analyzing and storing the blood samples for mercury concentrations. 


\section{References}

Adams JB, Romdalvik J, Ramanujam VM, Legator MS. Mercury, lead, and zinc in baby teeth of children with autism versus controls. J Toxicol Environm Health A. 2007; 70(12):10461051.10.1080/15287390601172080

Agency for Toxic Substances and Disease Registry. Toxicological profile for mercury. 1999. Retrieved from http://www.atsdr.cdc.gov/toxprofiles/tp.asp?id=115\&tid=24

American Psychiatric Association. Diagnostic and Statistical Manual of Mental Disorders, Fourth Edition Text Revision (DSM-IV-TR). American Psychiatric Publishing, Inc; Washington, DC: 2000.

Aschner M. Response to article by DeSoto and Hitlan on the relationship between mercury exposure and autism. J Child Neurol. 2008; 23(4):463. [PubMed: 18401039]

Autism and Developmental Disabilities Monitoring Network Surveillance Year 2006 Principal Investigators, Centers for Disease Control and Prevention. Prevalence of autism spectrum disorders —autism and developmental disabilities monitoring network, United States, 2006. MMWR Surveill Summ. 2009; 58(SS-10):1-24.

Axtell CD, Cox C, Myers GJ, Davidson PW, Choi AL, Cernichiari E, et al. Association between methylmercury exposure from fish consumption and child development at five and a half years of age in the Seychelles Child Development Study: an evaluation of nonlinear relationships. Environ Res. 2000; 84(2):71-80.10.1006/enrs.2000.4082 [PubMed: 11068920]

Berglund M, Lind B, Bjornberg KA, Palm B, Einarsson O, Vahter M. Inter-individual variations of human mercury exposure biomarkers: a cross-sectional assessment. Environ Health. 2005; 4:20.10.1186/1476-069X-4-20 [PubMed: 16202128]

Bilder D, Pinborough-Zimmerman J, Miller J, McMahon W. Prenatal, perinatal, and neonatal factors associated with autism spectrum disorders. Pediatrics. 2009; 123(5):1293-1300.10.1542/peds. 2008-0927 [PubMed: 19403494]

Blaxill MF, Baskin DS, Spitzer WO. Commentary: Blaxill, Baskin, and Spitzer on Croen et al. (2002), the changing prevalence of autism in California. J Autism Dev Disord. 2003; 33(2):223-226. [PubMed: 12757365]

Bose-O'Reilly S, McCarty KM, Steckling N, Lettmeier B. Mercury exposure and children's health. Curr Probl Pediatr Adolesc Health Care. 2010; 40(8):186-215.10.1016/j.cppeds.2010.07.002 [PubMed: 20816346]

Chakrabarti S, Fombonne E. Pervasive developmental disorders in preschool children: confirmation of high prevalence. Am J Psychiatry. 2005; 162(6):1133-1141. [PubMed: 15930062]

Chen WY, Wang YC, Kuo MS. Determination of total mercury and methylmercury in human hair by graphite-furnace atomic absorption spectrophotometry using 2,3-dimercaptopropane-1-sulfonate as a complexing agent. Anal Sci. 2002; 18(3):255-260. [PubMed: 11918181]

Chess S, Fernandez P, Korn S. Behavioral consequences of congenital rubella. J Pediatr. 1978; 93(4): 699-703. [PubMed: 702254]

Christianson AL, Chesler N, Kromberg JG. Fetal valproate syndrome: clinical and neurodevelopmental features in two sibling pairs. Dev Med Child Neurol. 1994; 36(4):361-369. [PubMed: 7512516]

Clarkson TW, Magos L, Myers GJ. The toxicology of mercury-current exposures and clinical manifestations. New Engl J Med. 2003; 349(18):1731-1737.10.1056/NEJMra02247 [PubMed: 14585942]

Counter SA, Buchanan LH. Mercury exposure in children: a review. Toxicol Appl Pharmacol. 2004; 198(2):209-230.10.1016/j.taap.2003.11.032 [PubMed: 15236954]

Counter SA, Buchanan LH, Ortega F, Laurell G. Elevated blood mercury and neuro-otological observations in children of the Ecuadorian gold mines. J Toxicol Environm Health A. 2002; 65(2): 149-163.10.1080/152873902753396785

Crespo-Lopez ME, de Lima SA, Herculano AM, Rodriguez BR, Martins do Nascimento JL. Methylmercury genotoxicity: a novel effect in human cell lines of the central nervous system. Environ Int. 2007; 33(2):141-146.10.1016/j.envint.2006.08.005 [PubMed: 17007929] 
Croen LA, Grether JK, Hoogstrate J, Selvin S. The changing prevalence of autism in California. J Autism Dev Disord. 2002a; 32(3):207-215. [PubMed: 12108622]

Croen LA, Grether JK, Selvin S. Descriptive epidemiology of autism in a California population: Who is at risk? J Autism Dev Disord. 2002b; 32(3):217-224.10.1023/A:1015405914950 [PubMed: 12108623]

D'Amelio M, Ricci I, Sacco R, Liu X, D'Agruma L, Muscarella LA, et al. Paraoxonase gene variants are associated with autism in North America, but not in Italy: possible regional specificity in geneenvironment interactions. Mol Psychiatry. 2005; 10(11):1006-1016.10.1038/sj.mp.4001714 [PubMed: 16027737]

Davidson PW, Myers GJ, Cox C, Axtell C, Shamlaye C, Sloane-Reeves J, et al. Effects of prenatal and postnatal methylmercury exposure from fish consumption on neurodevelopment: outcomes at 66 months of age in the Seychelles Child Development Study. JAMA. 1998; 280(8):701-707. [PubMed: 9728641]

Davidson PW, Cory-Slechta DA, Thurston SW, Huang LS, Shamlaye CF, Gunzler D, et al. Fish consumption and prenatal methylmercury exposure: cognitive and behavioral outcomes in the main cohort at 17 years from the Seychelles child development study. Neurotoxicology. 2011; 32(6):711-717.10.1016/j.neuro.2011.08.003 [PubMed: 21889535]

Debes F, Budtz-Jorgensen E, Weihe P, White RF, Grandjean P. Impact of prenatal methylmercury exposure on neurobehavioral function at age 14 years. Neurotoxicol Teratol. 2006; 28(3):363375.10.1016/j.ntt.2006.02.004 [PubMed: 16647838]

DeSoto MC, Hitlan RT. Blood levels of mercury are related to diagnosis of autism: a reanalysis of an important data set. J Child Neurol. 2007; 22(11):1308-1311. [PubMed: 18006963]

DeSoto MC, Hitlan RT. Concerning blood mercury levels and autism: a need to clarify. J Child Neurol. 2008; 23(4):46a-463.

Diez S, Delgado S, Aguilera I, Astray J, Perez-Gomez B, Torrent M, et al. Prenatal and early childhood exposure to mercury and methylmercury in Spain, a high-fish-consumer country. Arch Environ Contam Toxicol. 2009; 56(3):615-622.10.1007/s00244-008-9213-7 [PubMed: 18836676]

Dixon, DR.; Garcia, MJ.; Granpeesheh, D.; Tarbox, J. Differential diagnosis in autism spectrum disorders. In: Matson, JL., editor. Applied behavior analysis for children with autism spectrum disorders. Springer; New York: 2009. p. 83-108.

Dorea JG. Fish meal in animal feed and human exposure to persistent bioaccumulative and toxic substances. J Food Prot. 2006; 69(11):2777-2785. [PubMed: 17133828]

Dorea JG. Persistent, bioaccumulative and toxic substances in fish: human health considerations. Sci Total Environ. 2008; 400(1-3):93-114.10.1016/j.scitotenv.2008.06.017 [PubMed: 18653214]

Dorea JG. Studies of fish consumption as source of methylmercury should consider fish-meal-fed farmed fish and other animal foods. Environ Res. 2009; 109(1):131-132.10.1016/j.envres. 2008.10.004 [PubMed: 19027108]

Durkin MS, Maenner MJ, Newschaffer CJ, Lee LC, Cunniff CM, Daniels JL, et al. Advanced parental age and the risk of autism spectrum disorder. Am J Epidemiol. 2008; 168(11):1268-1276.10.1093/ aje/kwn250 [PubMed: 18945690]

FDA. Thimerosal in vaccines. Food and drug administration; 2010. Retrieved from http:// www.fda.gov/BiologicsBloodVaccines/SafetyAvailability/VaccineSafety/UCM096228\#t1

FDA. Mercury levels in commercial fish and shellfish (1990-2010). Food and drug administration; 2011. Retrieved from http://www.fda.gov/food/foodsafety/product-specificinformation/seafood/ foodbornepathogenscontaminants/methylmercury/ucm115644.htm

Fedorova I, Salem N Jr. Omega-3 fatty acids and rodent behavior. Prostaglandins Leukot Essent Fatty Acids. 2006; 75(4-5):271-289.10.1016/j.plefa.2006.07.006 [PubMed: 16973342]

Fido A, Al-Saad S. Toxic trace elements in the hair of children with autism. Autism. 2005; 9(3):290298. [PubMed: 15937043]

Folstein SE, Rosen-Sheidley B. Genetics of autism: complex aetiology for a heterogeneous disorder. Nat Rev Genet. 2001; 2(12):943-955.10.1038/35103559 [PubMed: 11733747]

Food Standards Australia New Zealand. Mercury in fish. 2011. Retrieved from http:// www.foodstandards.gov.au/consumerinformation/mercuryinfish.cfm 
Freire C, Ramos R, Lopez-Espinosa MJ, Diez S, Vioque J, Ballester F, et al. Hair mercury levels, fish consumption, and cognitive development in preschool children from Granada, Spain. Environ Res. 2010; 110(1):96-104.10.1016/j.envres.2009.10.005 [PubMed: 19909946]

Gardener H, Spiegelman D, Buka SL. Perinatal and neonatal risk factors for autism: a comprehensive meta-analysis. Pediatrics. 2011; 128(2):344-355.10.1542/peds.2010-1036 [PubMed: 21746727]

Genuis SJ. Is autism reversible? Acta Paediatr. 2009; 98(10):1575-1578.10.1111/j. 1651-2227.2009.01495.x [PubMed: 19843021]

Ginsberg GL, Toal BF. Quantitative approach for incorporating methylmercury risks and omega-3 fatty acid benefits in developing species-specific fish consumption advice. Environ Health Perspect. 2009; 117(2):267-275.10.1289/ehp.11368 [PubMed: 19270798]

Grandjean P, Weihe P, White RF, Debes F, Araki S, Yokoyama K, et al. Cognitive deficit in 7-yearold children with prenatal exposure to methylmercury. Neurotoxicol Teratol. 1997; 19(6):417428. [PubMed: 9392777]

Hallmayer J, Cleveland S, Torres A, Phillips J, Cohen B, Torigoe T, et al. Genetic heritability and shared environmental factors among twin pairs with autism. Arch Gen Psychiatry. 2011; 68(11): 1095-1102.10.1001/archgenpsychiatry.2011.76 [PubMed: 21727249]

Harada M. Minamata disease: ethylmercury poisoning in Japan caused by environmental pollution. Crit Rev Toxicol. 1995; 25(1):1-24.10.3109/10408449509089885 [PubMed: 7734058]

Hertz-Picciotto I, Delwiche L. The rise in autism and the role of age at diagnosis. Epidemiology. 2009; 20(1):622-623.

Hertz-Picciotto I, Green PG, Delwiche L, Hansen R, Walker C, Pessah IN. Blood mercury concentrations in CHARGE Study children with and without autism. Environ Health Perspect. 2010; 118(1):161-166.10.1289/ehp.0900736 [PubMed: 20056569]

Horvath K, Perman JA. Autistic disorder and gastrointestinal disease. Curr Opin Pediatr. 2002; 14(5): 583-587. [PubMed: 12352252]

Howe A, Fung LH, Lalor G, Rattray R, Vutchkov M. Elemental composition of Jamaican foods 1: a survey of five food crop categories. Environ Geochem Health. 2005; 27(1):19-30.10.1007/ s10653-004-5671-7 [PubMed: 15688127]

Hughes JR. A review of recent reports on autism: 1000 studies published in 2007. Epilepsy Behav. 2008; 13(3):425-437.10.1016/j.yebeh.2008.06.015 [PubMed: 18627794]

Hultman CM, Sparen P, Cnattingius S. Perinatal risk factors for infantile autism. Epidemiology. 2002; 13(4):417-423. [PubMed: 12094096]

Ibrahim SH, Voigt RG, Katusic SK, Weaver AL, Barbaresi WJ. Incidence of gastrointestinal symptoms in children with autism: a population-based study. Pediatrics. 2009; 124(2):680-686. [PubMed: 19651585]

Ip P, Wong V, Ho M, Lee J, Wong W. Mercury exposure in children with autistic spectrum disorder: case-control study. J Child Neurol. 2004; 19(6):431-434. [PubMed: 15446391]

Jakus, P.; Krupnick, AJ. Resources for the Future. The benefits and costs of fish consumption advisories for mercury. 2002. Retrieved from Resources for the Future http://www.rff.org/ documents/RFF-DP-02-55.pdf

Jedrychowski W, Perera F, Jankowski J, Rauh V, Flak E, Caldwell KL, et al. Fish consumption in pregnancy, cord blood mercury level and cognitive and psychomotor development of infants followed over the first three years of life: Krakow epidemiologic study. Environ Int. 2007; 33(8): 1057-1062.10.1016/j.envint.2007.06.001 [PubMed: 17643489]

Julvez J, Debes F, Weihe P, Choi A, Grandjean P. Sensitivity of continuous performance test (CPT) at age 14 years to developmental methylmercury exposure. Neurotoxicol Teratol. 2010; 32(6):627632.10.1016/j.ntt.2010.08.001 [PubMed: 20699117]

Kalmijn S, van Boxtel MP, Ocke M, Verschuren WM, Kromhout D, Launer LJ. Dietary intake of fatty acids and fish in relation to cognitive performance at middle age. Neurology. 2004; 62(2):275280. [PubMed: 14745067]

Kern JK, Grannemann BD, Trivedi MH, Adams JB. Sulfhydryl-reactive metals in autism. J Toxicol Environm Health A. 2007; 70(8):715-721.

King M, Bearman P. Diagnostic change and the increased prevalence of autism. Int J Epidemiol. 2009; 38(5):1224-1234. [PubMed: 19737791] 
King MD, Bearman PS. Socioeconomic status and the increased prevalence of autism in California. Am Sociol Rev. 2011; 76(2):320-346.10.1177/0003122411399389 [PubMed: 21547238]

Knight C, Kaiser J, Lalor GC, Robotham H, Witter JV. Heavy metals in surface water and stream sediments in Jamaica. Environ Geochem Health. 1997; 19(2):63-66.10.1023/A:1018442219943

Knobeloch LM, Ziarnik M, Anderson HA, Dodson VN. Imported seabass as a source of mercury exposure: a Wisconsin case study. Environ Health Perspect. 1995; 103(6):604-606. [PubMed: 7556015]

Kris-Etherton PM, Harris WS, Appel LJ. Fish consumption, fish oil, omega-3 fatty acids, and cardiovascular disease. Circulation. 2002; 106(21):2747-2757. [PubMed: 12438303]

Kumar R, Christian S. Genetics of autism spectrum disorders. Curr Neurol Neurosci Rep. 2009; 9(3): 188-197.10.1007/s11910-009-0029-2 [PubMed: 19348707]

Lakshmi Priya M, Geetha A. Level of trace elements (copper, zinc, magnesium and selenium) and toxic elements (lead and mercury) in the hair and nail of children with autism. Biol Trace Elem Res. 2010; 142(2):148-158. [PubMed: 20625937]

Lalor GC. Geochemical mapping in Jamaica. Environ Geochem Health. 1996; 18(3):89-97.10.1007/ BF01771284 [PubMed: 24194384]

Lando AM, Zhang Y. Awareness and knowledge of methyl-mercury in fish in the United States. Environ Res. 2011; 111(3):442-450.10.1016/j.envres.2011.01.004 [PubMed: 21257163]

Landrigan PJ. What causes autism? Exploring the environmental contribution. Curr Opin Pediatr. 201010.1097/MOP.0b013e328336eb9a

Larsson HJ, Eaton WW, Madsen KM, Vestergaard M, Olesen AV, Agerbo E, et al. Risk factors for autism: perinatal factors, parental psychiatric history, and socioeconomic status. Am J Epidemiol. 2005; 161(10):916-925. [PubMed: 15870155]

Llop S, Guxens M, Murcia M, Lertxundi A, Ramon R, Riano I, et al. Prenatal exposure to mercury and infant neurodevelopment in a multicenter cohort in Spain: study of potential modifiers. Am J Epidemiol. 201210.1093/aje/kwr328

Lord, C.; Rutter, M.; DiLavore, PC.; Risi, S. Autism diagnostic observation schedule (ADOS). Western Psychological Services; Los Angeles: 2002.

MacLean CH, Issa AM, Newberry SJ, Mojica WA, Morton SC, Garland RH, et al. Effects of omega-3 fatty acids on cognitive function with aging, dementia, and neurological diseases. Evid Rep Technol Assess (Summ). 2005; 114:1-3. [PubMed: 15777112]

Magos L, Clarkson TW. Overview of the clinical toxicity of mercury. Ann Clin Biochem. 2006; 43(Pt 4):257-268.10.1258/000456306777695654 [PubMed: 16824275]

Marsh DO, Myers GJ, Clarkson TW, Amin-Zaki L, Tikriti S, Majeed MA. Fetal methylmercury poisoning: clinical and toxicological data on 29 cases. Ann Neurol. 1980; 7(4):348-353.10.1002/ ana.410070412 [PubMed: 7377761]

Monrroy SX, Lopez RW, Roulet M, Benefice E. Lifestyle and mercury contamination of Amerindian populations along the Beni River (lowland Bolivia). J Environ Health. 2008; 71(4):44-50. [PubMed: 19004394]

Mozaffarian D. Fish, mercury, selenium and cardiovascular risk: current evidence and unanswered questions. Int J Environ Res Public Health. 2009; 6:1894-1916.10.3390/ijerph6061894 [PubMed: 19578467]

Murata K, Weihe P, Renzoni A, Debes F, Vasconcelos R, Zino F, et al. Delayed evoked potentials in children exposed to methylmercury from seafood. Neurotoxicol Teratol. 1999; 21(4):343-348. [PubMed: 10440477]

Myers GJ, Davidson PW, Palumbo D, Shamlaye C, Cox C, Cernichiari E, et al. Secondary analysis from the Seychelles Child Development Study: the child behavior checklist. Environ Res. 2000; 84(1):12-19.10.1006/enrs.2000.4085 [PubMed: 10991778]

Myers GJ, Thurston SW, Pearson AT, Davidson PW, Cox C, Shamlaye CF, et al. Postnatal exposure to methyl mercury from fish consumption: a review and new data from the Seychelles Child Development Study. Neurotoxicology. 2009; 30(3):338-349.10.1016/j.neuro.2009.01.005 [PubMed: 19442817] 
National Research Council. Toxicological effects of methyl-mercury. National Academy Press; Washington, DC: 2000. Retrieved from http://www.nap.edu/openbook.php? record_id=9899\&page=R1

$\mathrm{Ng}$ DK, Chan CH, Soo MT, Lee RS. Low-level chronic mercury exposure in children and adolescents: meta-analysis. Pediatr Int. 2007; 49(1):80-87.10.1111/j.1442-200X.2007.02303.x [PubMed: 17250511]

Northeast States for Coordinated Air Use Management. Mercury emission from coal-fired power plants. Boston, Massachusetts: NESCAUM; 2003. Retrieved from http://www.google.com/url? $\mathrm{sa}=\mathrm{t} \& \mathrm{rct}=\mathrm{j} \& \mathrm{q}=\mathrm{coal}-$ fired $\% 20$ power $\% 20$ plants $\% 20 \% 26 \% 20$ mercury \&source $=$ web $\& c d=1 \&$ ved $=0$ CDAQFjAA\&url $=$ http $\% 3 \mathrm{~A} \% 2 \mathrm{~F}$ $\% 2$ Fwww.nescaum.org\%2Fdocuments\%2Frpt031104mercury.pdf\%2F\&ei=4AeT_WcHIvFsQLfx_SeDg\&usg=AFQjCNHt6Fi8L4-vytQVJ4v3ruRiYmgdUA

Oken E, Bellinger DC. Fish consumption, methylmercury and child neurodevelopment. Curr Opin Pediatr. 2008; 20(2):178-183.10.1097/MOP.0b013e3282f5614c [PubMed: 18332715]

Oken E, Wright RO, Kleinman KP, Bellinger D, Amarasiriwardena CJ, Hu H, et al. Maternal fish consumption, hair mercury, and infant cognition in a U.S. Cohort. Environ Health Perspect. 2005; 113(10):1376-1380. [PubMed: 16203250]

Palmer RF. Conclusions should be based on appropriate methodologies. Pediatrics. 2010; 126(5) eLetter, Retrieved from http://pediatrics.aappublications.org/content/126/4/656\#responses.

Pennsylvania Fish and Boat Commission. Commonwealth of Pennsylvania public health advisory 2012 fish consumption. 2012. Retrieved from Pennsylvania Summary of Fishing Regulations and Laws http://fishandboat.com/fishpub/summary/sumconsumption.pdf

Rahbar MH, Samms-Vaughan M, Loveland KA, Pearson DA, Bressler J, Chen Z, et al. Maternal and paternal age are jointly associated with childhood autism in Jamaican. J Autism Dev Disord. 201210.1007/s10803-011-1438-z

Rapin I. Autism. N Engl J Med. 1997; 337(2):97-104. [PubMed: 9211680]

Reichenberg A, Gross R, Weiser M, Bresnahan M, Silverman J, Harlap S, et al. Advancing paternal age and autism. Arch Gen Psychiatry. 2006; 63(9):1026-1032. [PubMed: 16953005]

Rodier PM, Hyman SL. Early environmental factors in autism. Ment Retard Dev Disabil Res Rev. 1998; 4(2):121-128.

Rosner, B. Fundamental of biostatistics. 7. Thomson-Brooks/Cole; Belmont: 2010.

Rutter, M.; Bailey, A.; Lord, C. Manual. Western Psychological Services; Los Angeles: 2003a. SCQ: the Social Communication Questionnaire.

Rutter, M.; Le, CA.; Lord, C. Autism Diagnostic Interview-Revised (ADI-R). Western Psychological Services; Los Angeles: 2003b.

SAS Institute Inc. SAS ${ }^{\circledR}$ 9.2. SAS Institute Inc; Cary: 2008.

Sasanfar R, Haddad S, Tolouei A, Ghadami M, Yu D, Santangelo S. Paternal age increases the risk for autism in an Iranian population sample. Mol Autism. 2010; 1(1):2.10.1186/2040-2392-1-2 [PubMed: 20678245]

Schober SE, Sinks TH, Jones RL, Bolger PM, McDowell M, Osterloh J, et al. Blood mercury levels in US children and women of childbearing age, 1999-2000. JAMA. 2003; 289(13):1667-1674. [PubMed: 12672735]

Shelton JF, Tancredi DJ, Hertz-Picciotto I. Independent and dependent contributions of advanced maternal and paternal ages to autism risk. Autism Res. 2010; 3(1):30-39.10.1002/aur.116 [PubMed: 20143326]

Shimshack JP, Ward MB, Beatty TKM. Mercury advisories: information, education, and fish consumption. J Environ Econ Manag. 2007; 53(2):158-179.

Silbernagel SM, Carpenter DO, Gilbert SG, Gochfeld M, Groth E III, Hightower JM, et al. Recognizing and preventing overexposure to methylmercury from fish and seafood consumption: information for physicians. J Toxicol. 2011; 2011:983072.10.1155/2011/983072 [PubMed: 21785592]

Song JW, Chung KC. Observational studies: cohort and case-control studies. Plast Reconstr Surg. 2010; 126(6):2234-2242.10.1097/PRS.0b013e3181f44abc [PubMed: 20697313] 
Sontrop JM, Campbell MK, Evers SE, Speechley KN, Avison WR. Fish consumption among pregnant women in London, Ontario: associations with socio-demographic and health and lifestyle factors. Can J Public Health. 2007; 98(5):389-394. [PubMed: 17985681]

Stern AH, Korn LR. An approach for quantitatively balancing methylmercury risk and omega-3 benefit in fish consumption advisories. Environ Health Perspect. 2011; 119(8):10431046.10.1289/ehp.1002824 [PubMed: 21543281]

Steuerwald U, Weihe P, Jorgensen PJ, Bjerve K, Brock J, Heinzow B, et al. Maternal seafood diet, methylmercury exposure, and neonatal neurologic function. J Pediatr. 2000; 136(5):599_ 605.10.1067/mpd.2000.102774 [PubMed: 10802490]

The Centers for Disease Control and Prevention. Fourth National Report on Human Exposure to Environmental Chemicals. 2009a. Retrieved from http://www.cdc.gov/ExposureReport/

The Centers for Disease Control and Prevention. National Survey of Ambulatory Surgery Data Collection and Processing. Centers for Disease Control and Prevention (CDC); 2009b. Retrieved from http://www.cdc.gov/nchs/nsas/nsas_collection.htm

The Texas Department of State Health Services, US Department of Health and Human Services, Agency for Toxic Substances and Disease Registry. Mercury exposure investigation caddo lake area. The Texas Department of State Health Services; 2005.

Trondsen T, Scholderer J, Lund E, Eggen AE. Perceived barriers to consumption of fish among Norwegian women. Appetite. 2003; 41(3):301-314. [PubMed: 14637329]

Turyk ME, Bhavsar SP, Bowerman W, Boysen E, Clark M, Diamond M, et al. Risks and benefits of consumption of great lakes fish. Environ Health Perspect. 2012; 120(1):11-18.10.1289/ehp. 1003396 [PubMed: 21947562]

US Environmental Protection Agency. Mercury in dental amalgam. 2011a. Retrieved from http:// www.epa.gov/hg/dentalamalgam.html

US Environmental Protection Agency. Thermometers. 2011b. Retrieved from http://www.epa.gov/ mercury/thermometer-main.html

Valicenti-McDermott M, McVicar K, Rapin I, Wershil BK, Cohen H, Shinnar S. Frequency of gastrointestinal symptoms in children with autistic spectrum disorders and association with family history of autoimmune disease. J Dev Behav Pediatr. 2006; 27(2 Suppl):S128-S136. [PubMed: 16685179]

Vinot N, Jouin M, Lhomme-Duchadeuil A, Guesnet P, Alessandri JM, Aujard F, et al. Omega-3 fatty acids from fish oil lower anxiety, improve cognitive functions and reduce spontaneous locomotor activity in a non-human primate. PLoS One. 2011; 6(6):e20491.10.1371/journal.pone.0020491 [PubMed: 21666750]

Volkmar FR, Chawarska K. Autism in infants: an update. World Psychiatry. 2008; 7(1):19-21. [PubMed: 18458791]

Volkmar F, Chawarska K, Klin A. Autism in infancy and early childhood. Annu Rev Psychol. 2005; 56:315-336.10.1146/annurev.psych.56.091103.070159 [PubMed: 15709938]

Wilhelm M, Schulz C, Schwenk M. Revised and new reference values for arsenic, cadmium, lead, and mercury in blood or urine of children: basis for validation of human biomonitoring data in environmental medicine. Int J Hyg Environ Health. 2006; 209(3):301-305. [PubMed: 16739256]

Wong SL, Lye EJ. Lead, mercury and cadmium levels in Canadians. Health Rep. 2008; 19(4):31-36. [PubMed: 19226925]

Xue F, Holzman C, Rahbar MH, Trosko K, Fischer L. Maternal fish consumption, mercury levels, and risk of preterm delivery. Environ Health Perspect. 2007; 115(1):42-47. [PubMed: 17366817] 
Table 1

Demographic and SES characteristics of children and their parents by ASD case status

\begin{tabular}{|c|c|c|c|c|}
\hline Variables & Categories & $\begin{array}{c}\text { Case }(n=65) \\
N(\%)\end{array}$ & $\begin{array}{c}\text { Control }(n=65) \\
N(\%)\end{array}$ & $P$ value \\
\hline \multirow[t]{3}{*}{ Age of child ${ }^{a}$ (months) } & Age $<48$ & $10(15.4)$ & $9(13.8)$ & 0.85 \\
\hline & $48 \leq$ age $<72$ & $34(52.3)$ & $34(52.3)$ & \\
\hline & Age $\geq 72$ & $21(32.3)$ & $22(33.9)$ & \\
\hline \multirow[t]{2}{*}{ Maternal education (at child's birth) } & Up to high school & $34(52.3)$ & $51(81.0)$ & $<0.01$ \\
\hline & Beyond high school & $31(47.7)$ & $12(19.0)$ & \\
\hline \multirow[t]{2}{*}{ Paternal education (at child's birth) } & Up to high school & $32(50.8)$ & $56(91.8)$ & $<0.01$ \\
\hline & Beyond high school & $31(49.2)$ & $5(8.2)$ & \\
\hline \multirow[t]{2}{*}{ Number of children in the household (age $\leq 18$ years) } & $1-2$ & $53(81.5)$ & $34(52.3)$ & $<0.01$ \\
\hline & $\geq 3$ & $12(18.5)$ & $31(47.7)$ & \\
\hline \multirow[t]{2}{*}{ Number of adults in the household (age $>18$ years) } & $1-2$ & $42(64.6)$ & $38(59.4)$ & 0.58 \\
\hline & 23 & $23(35.4)$ & $27(40.6)$ & \\
\hline \multirow[t]{8}{*}{ Assets owned } & TV & $65(100.0)$ & $62(95.4)$ & NR \\
\hline & Refrigerator & $65(100.0)$ & $54(83.1)$ & NR \\
\hline & Freezer & $8(12.3)$ & $12(18.8)$ & 0.35 \\
\hline & Living room set & $57(87.7)$ & $31(47.7)$ & $<0.01$ \\
\hline & Washing machine & $54(83.1)$ & $33(50.8)$ & $<0.01$ \\
\hline & Cars or other vehicles & $45(69.2)$ & $22(33.8)$ & $<0.01$ \\
\hline & Telephone/cell phone & $63(98.4)$ & $65(100.0)$ & NR \\
\hline & Cable/satellite connection & $46(70.8)$ & $22(33.8)$ & $<0.01$ \\
\hline
\end{tabular}

Up to high school education: attended Primary/Jr. Secondary, and Secondary/High/Technical schools

Beyond high school: attended a Vocational, Tertiary College, or University

NR: not reported due to unstable estimates caused by no observations in at least one cell

Maternal education was missing for 2 controls

Paternal education was missing for 2 cases and 4 controls

Number of adults in the household was missing for 1 control family

Assets owned (freezer) was missing for 1 control family

Assets owned (telephone/cell phone) was missing for 1 case family

${ }^{a}$ Age of the controls is within 6 months of their matched cases 


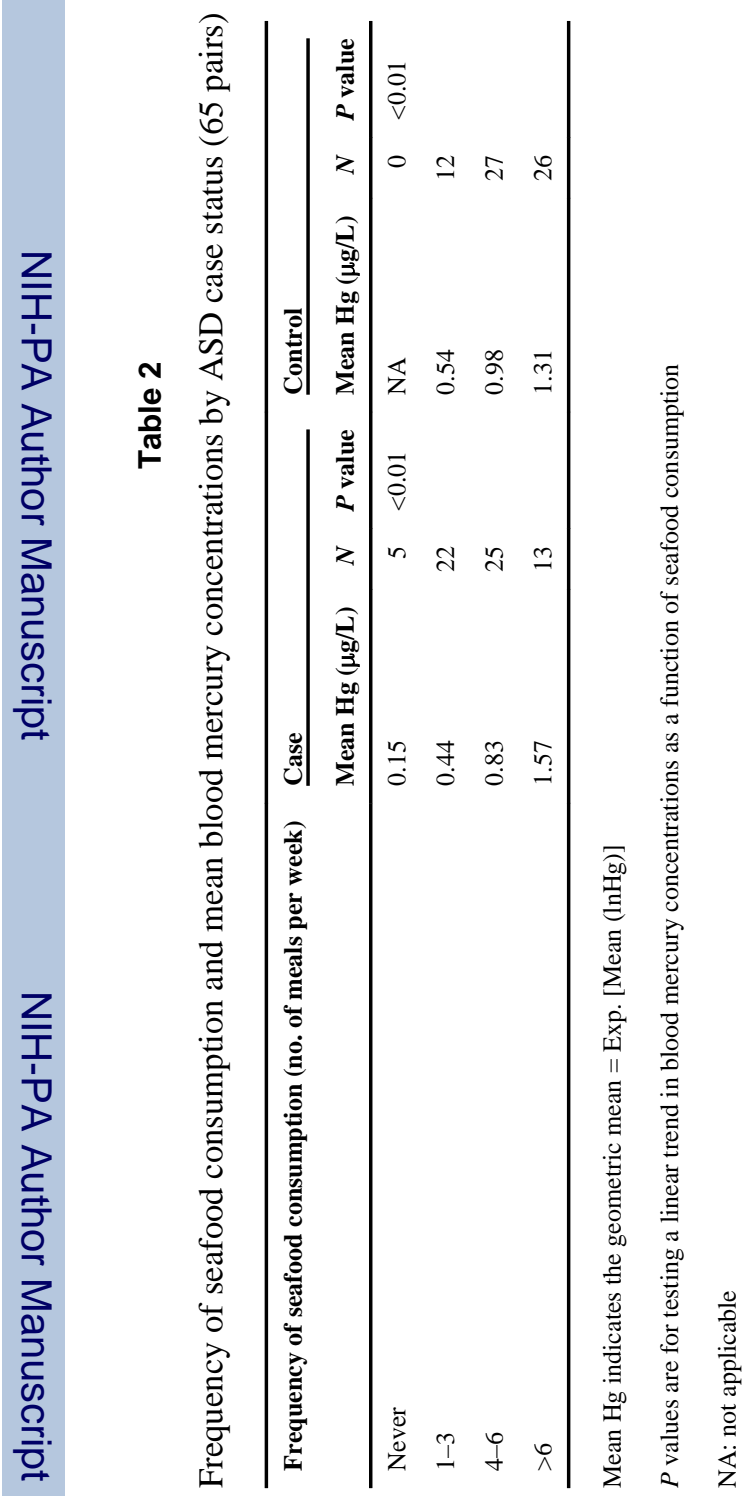

Neurotox Res. Author manuscript; available in PMC 2014 March 28. 
Table 4

Factors associated with blood mercury concentration using GLM (65 pairs)

\begin{tabular}{|c|c|c|c|c|}
\hline Exposure variables & Category & $\begin{array}{l}\text { Yes } \\
\text { Mean Hg }(\mu \mathrm{g} / \mathrm{L})\end{array}$ & $\begin{array}{l}\text { No } \\
\text { Mean Hg }(\mu \mathrm{g} / \mathrm{L})\end{array}$ & $P$ value \\
\hline Child's sex & Male & 0.73 & 1.54 & 0.42 \\
\hline Child's age & More than 4 years & 0.71 & 1.71 & 0.51 \\
\hline $\begin{array}{l}\text { Paternal age (years) (at child's } \\
\text { birth) }\end{array}$ & More than 35 years & 0.66 & 0.87 & 0.30 \\
\hline $\begin{array}{l}\text { Maternal age (years) (at child's } \\
\text { birth) }\end{array}$ & More than 35 years & 0.52 & 0.88 & 0.07 \\
\hline $\begin{array}{l}\text { Parental education levels (at } \\
\text { child's birth) }\end{array}$ & $\begin{array}{l}\text { At least one of the parents had education beyond high } \\
\text { school }\end{array}$ & 0.61 & 1.01 & 0.04 \\
\hline \multirow[t]{11}{*}{ Seafood consumption } & $\begin{array}{l}\text { High seafood consumption (more than } 6 \text { meals per } \\
\text { week) }\end{array}$ & 1.60 & 0.61 & $<0.01$ \\
\hline & Frequency of seafood meals consumed weekly & NA & NA & $<0.01$ \\
\hline & Ate seafood & 0.89 & 0.07 & $<0.01$ \\
\hline & Ate any fish & 0.90 & 0.10 & $<0.01$ \\
\hline & Ate salt water fish & 0.95 & 0.41 & $<0.01$ \\
\hline & Ate fresh water fish (pond fish, tilapia) & 1.01 & 0.69 & 0.10 \\
\hline & Ate sardine, mackerel (canned fish) & 0.96 & 0.41 & $<0.01$ \\
\hline & Ate tuna (canned fish) & 1.10 & 0.69 & 0.05 \\
\hline & Ate salt fish (pickled mackerel) & 0.91 & 0.50 & 0.04 \\
\hline & Ate shellfish (lobsters, crabs) & 3.21 & 0.75 & $<0.01$ \\
\hline & Ate shrimp & 1.16 & 0.75 & 0.13 \\
\hline
\end{tabular}

NA: not applicable, because frequency of seafood meals consumed weekly is analyzed as a continuous variable

The Yes column includes subjects who met the category specified in front of each exposure variable

The No column includes subjects who did not meet the category specified in front of each exposure variable

Mean $\mathrm{Hg}$ indicates the geometric mean = Exp. [Mean $(\mathrm{lnHg})]$ 
Table 5

Unadjusted and adjusted mean blood mercury concentrations for 65 cases and their matched controls based on the GLMs

\begin{tabular}{llll}
\hline & Mean Hg cases $(\mu \mathrm{g} / \mathbf{L})$ & Mean Hg controls $(\mu \mathrm{g} / \mathbf{L})$ & $\boldsymbol{P}$ value \\
\hline Unadjusted & 0.67 & 0.99 & 0.02 \\
Adjusted & 0.75 & 0.82 & 0.61 \\
\hline
\end{tabular}

${ }^{a}$ Factors adjusted for in the GLM include: frequency of seafood consumption per week, parental education levels, and maternal age Mean $\mathrm{Hg}$ indicates the geometric mean = Exp. [Mean $(\mathrm{lnHg})]$

$P$ values are based on the log-transformed blood mercury concentrations 